\title{
Assessing the impact sensitivity of explosives using the BHF-12A equipment
}

\author{
Cristian Rădeanu* , Daniela Carmen Rus, Ilie Ciprian Jitea, Claudia Miron , and Gabriel \\ Vasilescu
}

National Institute for Research and Development in Mine Safety and Protection to Explosion INSEMEX Petroşani Department of Safety Explosives and Pyrotechnic Aticles, 32-34 G-ral Vasile Milea St., 332047 - Petroşani, Hunedoara County, Romania

\begin{abstract}
The paper presents the results of the theoretical and practical research on the development of the technical and methodological infrastructure for assessing the safety parameter regarding the sensitivity to impact of explosives for civil use in order to increase the degree of security in their handling and use. The currently used method for determining the sensitivity to impact is based on the provisions of harmonized European Standard SR EN 13631-4. Expression of the results implies a particular experience of the research team, the conclusion of the test being in the form of a qualitative response reaction/non reaction to different energies (J) applied to the explosive samples, based on observed effects such as: smoke, explosion noise, flame / spark with or without combustion traces on the subassembly of the specialized test equipment. In order to carry out in good conditions the installation, use and maintenance of the specialized equipment for assessing the susceptibility of the tested substances to impact stimuli, the working procedure of the Department of Explosives and Pyrotechnic Products was elaborated and implemented, PL-04 working procedure with the designation "Working procedure for the installation, use and maintenance of $\mathrm{BFH}-12 \mathrm{~A}$ type equipment designed to assess the sensitivity of test substances to impact stimuli".
\end{abstract}

\section{Introduction}

Explosives are chemical compounds - substances or mixtures of substances that have a large amount of energy and which, under the influence of external action, break down suddenly, violently with heat release and gas formation capable of generating mechanical work. The decomposition of explosives is influenced by a number of factors: the nature and intensity of the initiation impulse; the space in which decomposition occurs, confined / unconfined; the amount of explosive substance subject to decomposition; the heat, temperature and pressure of the resulting products; decomposition velocity etc. Depending on the decomposition rate which may vary between a few millimetres per second and thousands of meters per second, we mainly distinguish the following decomposition reactions of explosives: detonation and deflagration (burning) [1].

\footnotetext{
Corresponding author: cristian.radeanu@insemex.ro
} 
Until detonation under the conditions for which they were developed, the explosives are pass through different stages: manufacturing, handling, transport, storage. Throughout the course of the explosives, having as their starting point manufacturing and end-use by the operator (authorized craftsman), these products may be / are subjected to various demands (friction or impact) that may endanger the life and health of persons and can destroy material goods, affect the environment etc. On this basis, the explosives must have a certain resistance to the demands arising from the handling, storage, loading into the holes and the transport [2].

Prior to use (making available on the market), explosives are subject to different laboratory tests to ensure compliance with the essential safety requirements applicable to each type and to match the ballistic / physic-chemical / thermodynamic parameters within specified manufacturer specific explosive ranges.

In order to evaluate all the parameters characterizing the explosives, there are different methods of verification / determination, most of them being standardized at European / national level, if we refer to the context in which INCD INSEMEX Petroşani is integrated [3].

The methods currently used for determining friction and impact sensitivity are based on the provisions of harmonized European standards SR EN 13631-3 and SR EN 13631-4 respectively. Expression of the results implies a special experience of the research team, the conclusion of the test being reaction / non-reaction, at various forces $(\mathrm{N}) /$ energies $(\mathrm{J})$ applied on explosive samples based on observed effects such as smoke, explosion noise, flame / spark with or without combustion traces on the stand assemblies.

\section{Determination of safety parameter for impact sensitivity, specific for explosives for civil use}

Impact sensitivity is the property of explosives to detonate by impact and is a parameter that characterizes the safety of explosives in handling and transport. It is expressed in Joules $(\mathrm{J})$, representing practically the minimum impact energy at which the explosion of the explosive sample occurs.

The test for determination of the impact sensitivity of explosives and detonating fuses is required in order to ensure the continued compliance with the requirements of Directive 2014/28 / EU transposed at national level by GD 197/2016 and the Technical Norms to Law No. 126 / 1995 with subsequent amendments and completions.

The method consists in the fall of a specified mass hammer, from a fixed height, on the explosive sample tested and the calculation of the minimum impact energy at which at least one reaction is obtained, out of six tests [4].

For the determination of the impact sensitivity, there was performed a test with a granular explosive consisting of a mixture of porous ammonium nitrate and diesel, type AUSTINITE manufactured by Austin Powder. The powdered granular substance was passed through a $0.5 \mathrm{~mm}$ sieve, for test was used the last fraction through this sieve.

For each test, a $40 \mathrm{~mm}^{3}$ cylindrical capacity measure $(3.7 \mathrm{~mm}$ in diameter and $3.7 \mathrm{~mm}$ in length) was taken a sample of the substance prepared according to the working procedure. The scope of the test method is within the range of $-30 \div+80 \mathrm{C}$, so no particular environmental conditions are required.

\subsection{Working manner}

Taking into account the provisions of the current regulations on explosives for civil use in various specific activities in which they are required, from the perspective of the use of the 
integrated concept of total safety for the technical infrastructure for the storage of civil use explosives and for other types of operations, the BAM Fall Hammer products, BFH-12A, purchased under Research Project PN-19 2102 02, is characterized by a gradation (impact energy from $0.25 \mathrm{~J}$ to $100 \mathrm{~J}$ ), being state-of-the-art in the field and able to meet, at the highest level and under economic efficiency conditions, the technical requirements imposed by applicable international / European and national regulations.

\subsection{Technical requirements of the BAM Fall Hammer, BFH-12A}

BAM Fall Hammer BFH-12A is equipped with the automated lifting mechanism which allows to remotely operate the positioning, dropping and collection of a drop weight via a touch screen of a remote control unit.

The equipment is fitted with a drop-down weight change window for a quick, easy and safe weight change.

Standard weights of $1.0 \mathrm{~kg}, 5.0 \mathrm{~kg}$ and $10.0 \mathrm{~kg}$, as well as weights of $0.25 \mathrm{~kg}, 0.5 \mathrm{~kg}$, $2.0 \mathrm{~kg}$ allows the impact sensitivity to be determined in the range of $0.25 \div 100$ Joules. 1.0 $\mathrm{kg}, 2.0 \mathrm{~kg} 5.0 \mathrm{~kg}$ and $10.0 \mathrm{~kg}$ weights are equipped with brass grooves to reduce sliding friction (drop weight of $0.25 \mathrm{~kg}$ and $0.5 \mathrm{~kg}$ is not provided with brass grooves) [4,5]. The guiding rails of the equipment are made of stainless steel.

\subsection{Equipment description}

The laboratory machine BAM Fall Hammer, BFH Series (Fig. 1) consists of two stainless steel guide rails (1); a release device (2); a column (3); three middle cross-piece (4); a drop weight (5); a tooth rack (6); a ruler (7); a main anvil $(8)$; a pedestal $(9,10)$ and further the protective housing which cover main anvil and working area and guards the operator against possible fragments of any parts generated by the impact device.

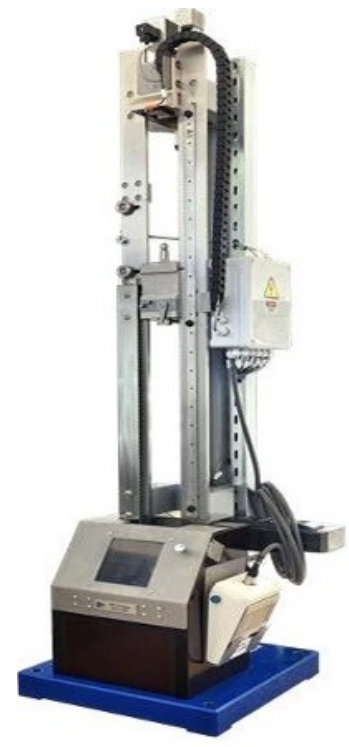

a.

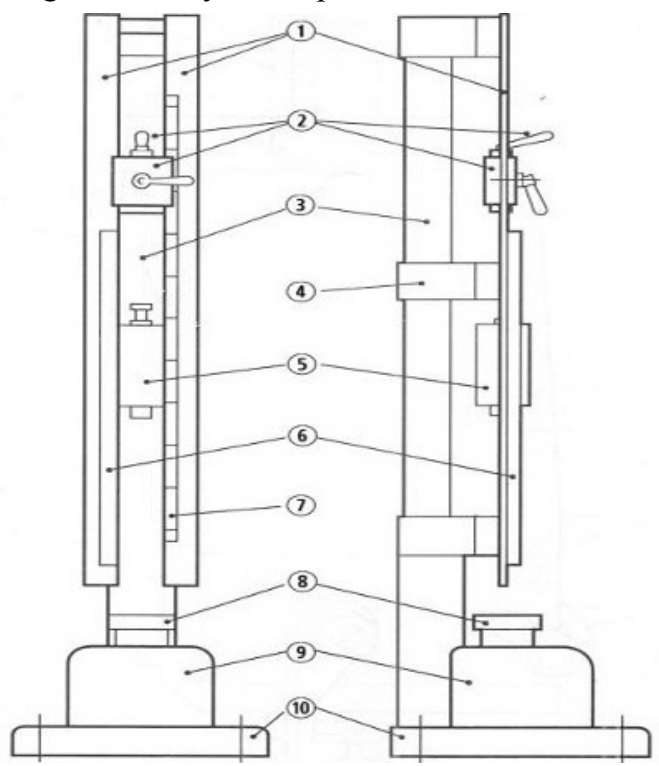

b.

Fig. 1. BFH-12A Machine: a. general view; b. front view; c. lateral view. 
BAM Fall Hammer BFH-12A is equipped with the automated lifting mechanism which allows to remotely operate the positioning, dropping and collection of a drop weight via a touch screen of a remote control unit.

Moreover, the machines BFH-12 and BFH-12A are equipped with a unique feature drop weight exchange window (Fig. 2). The exchange window is placed on the left guide rail and by it the drop weight can be exchanged faster, safer and in a more convenient way in comparison with standard BAM fall hammers machines.

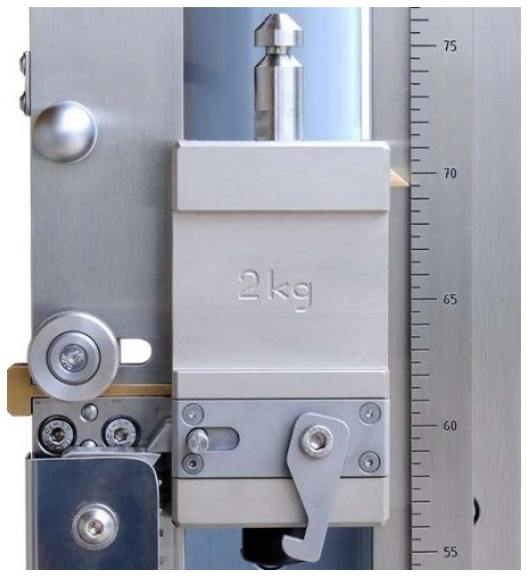

a.

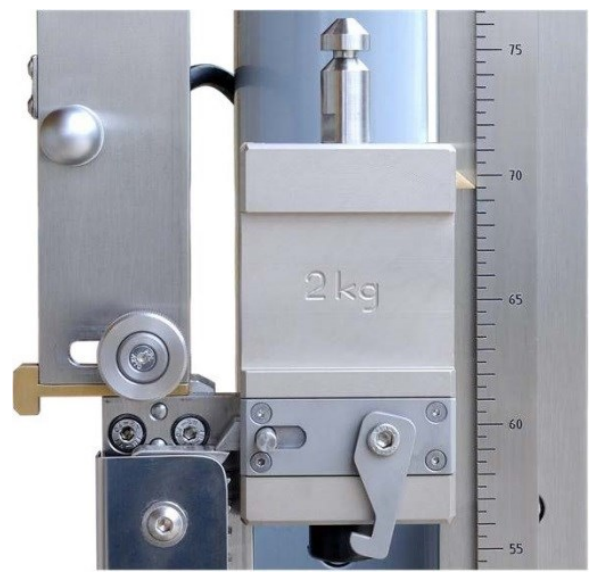

b.

Fig. 2. Drop weight exchange window: a. position Close; b. position Open.

The guide rails defined trajectory of falling drop weight. The release device allows to hold the drop weight in required position above the sample inside impact device.

The machine can be supplied with five drop weights with nominal value of weight 0.25 $\mathrm{kg} ; 0.5 \mathrm{~kg} ; 1 \mathrm{~kg} ; 2 \mathrm{~kg} ; 5 \mathrm{~kg}$ and $10 \mathrm{~kg}$

The protective housing can be connected to local laboratory ventilation system or the explosion-proof suction device for removal of any decomposition gases or dust from the housing. [5].

All movements of the release device or the drop weight are manage via main screen of the remote control unit (fig 3)

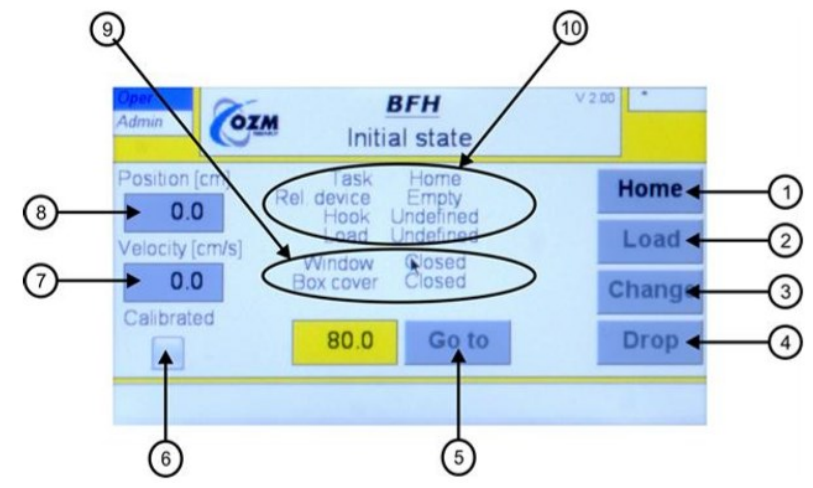

Fig. 3. Main Screen of Remote Control Unit.

Where,

(1) HOME - to adjust the Automated Lifting Mechanism;(2) LOAD - to load the drop weight with release device; (3) CHANGE - to move the drop weight to the Exchange Window and leave it there; (4) DROP - to fall down the drop weight onto the sample; (5) 
GO TO - to set the desired position of detached release device or in connection with the drop weight; (6) Displays if the positioning mechanism is calibrated; (7) Displays current velocity of movement; (8) If is in connection with the release device displays current position of the drop weight above the sample; (9) Signalize condition of limit switch of exchange window and protective housing door (10) Signalize last commanded TASK; state of release device (empty/loaded); state of Hook (undefined/locked) and group of drop weight(s) loaded in release device (light/medium/heavy) [5].

\subsection{Trial test performance}

According to the PL-04 working procedure entitled "Working procedure for the installation, use and maintenance of BFH-12A type equipment, designed to assess sensitivity of test substances to impact stimuli", certain steps shave to be performed:

- Attaching the impact device to the retaining bush on the intermediate anvil without the upper steel cylinder.

- Samples of the explosive substance, prepared according to the working procedure, shall be placed in the open impact device.

- Mounting the second (top) cylinder on top of the sample and pressing it gently until it reaches the sample, which can be felt due to a slight resistance, avoiding the sample being squeezed.

After placing the sample, the impact device is centred on the intermediate anvil, closing the protective housing (fig. 4). The test begins with impact energy of $10 \mathrm{~J}$ (hammer of $5 \mathrm{~kg}$, $20 \mathrm{~cm}$ drop height). The hammer is released following the behaviour of the sample and classifying the mode of expression into one of the following categories: Reaction (R) and No Reaction (WR).

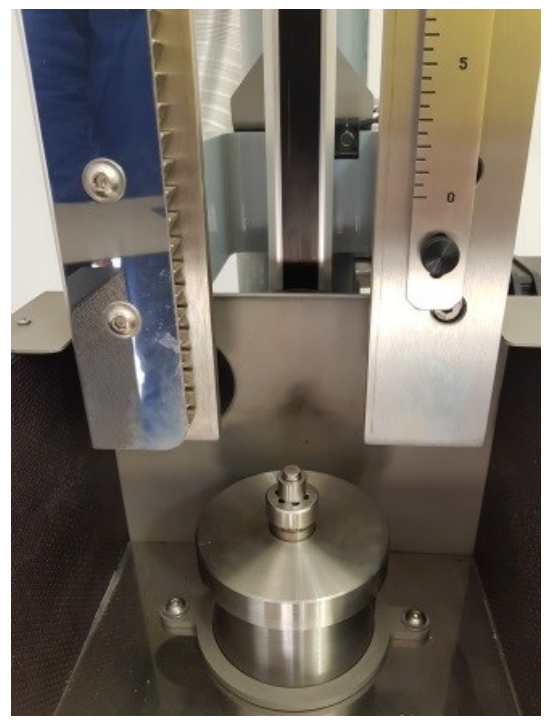

Fig. 4. Deployment of the impact device filled with the explosive substance sample in the impact test equipment.

As no reaction to the explosive sample (WR) was found, the test was repeated 5 times using the same drop weight ( $5 \mathrm{~kg}$ weight) as the fall height increased by $10 \mathrm{~cm}$ resulting in the following impact energies: $15 \mathrm{~J}(\mathrm{~h}=30 \mathrm{~cm}), 20 \mathrm{~J}(\mathrm{~h}=40 \mathrm{~cm}), 25 \mathrm{~J}(\mathrm{~h}=50 \mathrm{~cm}), 30 \mathrm{~J}(\mathrm{~h}=60$ $\mathrm{cm})$ and $35 \mathrm{~J}(\mathrm{~h}=70 \mathrm{~cm})$. 
Given the fact that for the impact energy of $35 \mathrm{~J}$ there was a reaction (R), (see Fig 5) then the test was repeated for a lower impact energy $(32.5 \mathrm{~J}$ at a drop height of $65 \mathrm{~cm})$, in which case also a $(\mathrm{R})$ reaction was also found.

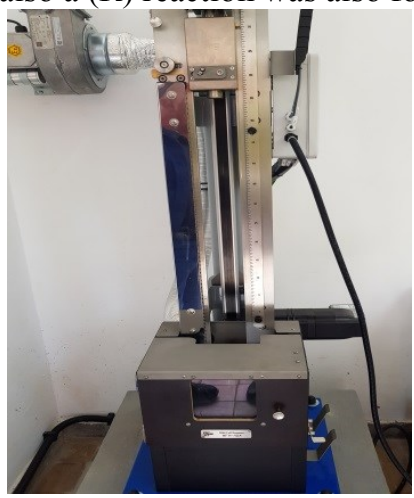

a.

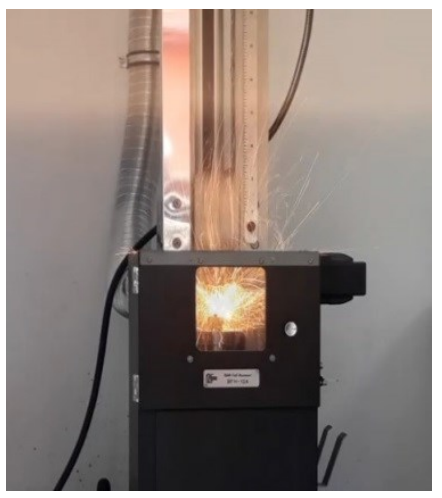

b.

Fig. 5. Performing the test, using the BFH-12A equipment with a $35 \mathrm{~J}$ impact energy, on the AUSTINITE type explosive: a. impact energy setting; $b$. the reaction resolution R-type.

Totally analogous, the test was repeated 6 times for lower impact energy (30 J at a drop height of $60 \mathrm{~cm}$ ), in which case no reaction on Explosive Sample was noted (WR) [6].

\section{Calculations, expression and evaluations of results}

The impact sensitivity $\mathrm{Si}$ (in $\mathrm{J}$ ) is the product of the mass of the drop weight $\mathrm{M}$ (in $\mathrm{kg}$ ) the drop height $\mathrm{h}$ (in $\mathrm{m}$ ) and the gravitational acceleration $\mathrm{g}$ (value $10 \mathrm{~m} / \mathrm{s} 2$ ) at least one reaction of 6 tests.

$$
S i=M x h \times g[J]
$$

The test method does not imply a calculation of uncertainty because the result is of a qualitative type, i.e. "with reaction" (R) or "without reaction" (WR).

Following the test to determine the sensitivity to impact of a granular explosive consisting of a mixture of porous ammonium nitrate and AUSTINITE type Diesel, minimum impact energy of $32.5 \mathrm{~J}$ resulted (Table 1 ).

Table 1. Results obtained in tests on the explosive type AUSTINITE.

\begin{tabular}{|l|c|c|c|c|c|}
\hline No. & $\begin{array}{c}\text { Drop weight M } \\
{[\mathrm{kg}]}\end{array}$ & $\begin{array}{c}\text { Drop height h } \\
{[\mathrm{m}]}\end{array}$ & $\begin{array}{c}\text { Room } \\
\text { temperature } \\
{\left[{ }^{0} \mathrm{C}\right]}\end{array}$ & $\begin{array}{c}\text { Result: } \\
\text { R-with reaction; } \\
\text { WR - without } \\
\text { reaction }\end{array}$ & $\begin{array}{c}\text { Impact } \\
\text { sensitivity } \\
\mathrm{S}_{\mathrm{i}}=\mathrm{M} \cdot \mathrm{h} \cdot \mathrm{g}[\mathrm{J}]\end{array}$ \\
\hline 1. & 5 & 0,20 & 18 & WR & 10,0 \\
\hline 2. & 5 & 0,30 & 18 & WR & 15,0 \\
\hline 3. & 5 & 0,40 & 18 & WR & 20,0 \\
\hline 4. & 5 & 0,50 & 18 & WR & 25,0 \\
\hline 5. & 5 & 0,60 & 18 & WR & 30,0 \\
\hline 6. & 5 & 0,70 & 18 & R & 35,0 \\
\hline 7. & 5 & 0,65 & 18 & R & 32,5 \\
\hline 8. & 5 & 0,60 & 18 & WR & 30,0 \\
\hline 9. & 5 & 0,60 & 18 & WR & 30,0 \\
\hline 10. & 5 & 0,60 & 18 & WR & 30,0 \\
\hline 11. & 5 & 0,60 & 18 & WR & 30,0 \\
\hline
\end{tabular}




\begin{tabular}{|l|l|l|l|l|l|}
\hline 12. & 5 & 0,60 & 18 & WR & 30,0 \\
\hline 13. & 5 & 0,60 & 18 & WR & 30,0 \\
\hline
\end{tabular}

Further, to illustrate the result indicators related to these parameters, a table summarizes them (Table 2).

Table 2. Impact sensitivity values for different types of explosives.

\begin{tabular}{|c|c|c|c|c|}
\hline No. & $\begin{array}{c}\text { Characteristics of } \\
\text { explosives }\end{array}$ & Value & Explosive name & Producer / supplier company \\
\hline 1. & \multirow{7}{*}{$\begin{array}{l}\text { Impact sensitivity } \\
(\mathrm{J})\end{array}$} & $>30,0 \mathrm{~J}$ & SWISS ANFO & SSE EXPLO ROMANIA \\
\hline 2. & & $>50,0 \mathrm{~J}$ & RIOGEL TRONER HE & MAXAM Romania \\
\hline 3. & & $>47,5 \mathrm{~J}$ & ANFODET 2 & EXPLOMIN \\
\hline 4. & & $>7,50 \mathrm{~J}$ & SEMTEX 10 & NITRO NOBEL SRL \\
\hline 5. & & $>45,0 \mathrm{~J}$ & ABS ANFO & CAVIEM LINE \\
\hline 6. & & $>12,5 \mathrm{~J}$ & NAPOEX & NAPOCAMIN \\
\hline 7. & & $>27,5 \mathrm{~J}$ & RIOGEL SB & $\begin{array}{c}\text { MAXAM ANADOLU } \\
\text { Turkey }\end{array}$ \\
\hline
\end{tabular}

\section{Conclusions}

Until detonation under the conditions for which they were made, the explosives are in pas through various stages: manufacturing, handling, transportation, storage. Throughout this course of the explosives, having as starting point manufacturing and end-use by the operator (authorized craftsman), these products may be / are subjected to various demands (friction or impact) that may endanger the life and health of persons and can destroy material goods, affect the environment etc. On this basis, explosives must have a certain resistance to the demands arising from the handling, storage, loading into the holes and the transport. Because the kinds of explosives used in industry are related to the nature of the environments in which they will detonate, knowing the parameters that characterize the explosives is essential whether we are referring to ensuring the maximum safety conditions of blasting works or if we are referring to the other parameters such as thermodynamic, physico-chemical, or ballistics ones for achieving the proposed safety objective.

Prior to use (making available on the market), explosives are subject to different laboratory tests to ensure the compliance with the essential safety requirements applicable to each type and to match the ballistic / physico-chemical / thermodynamic parameters within specified manufacturer specific explosive ranges.

This paper was developed within the NUCLEU - Programme, carried out with the support of ANCSI, Project no. PN-19 210202.

\section{References}

1. G. Berta, Explosives - an Engineering Tool (Ital Esplosivi, Milan, 1990)

2. R. Holmberg, Explosives and Blasting Technique, (Swets \& Zeitlinger B.V., Lisse, 2003)

3. C. Jitea, C. Lupu, M. Suvar, D. Rus, Environmental Engineering and Management Journal 13, 1459-1462 (2014)

4. Standard SR EN 13631-4 (2003)

5. User manual BAM Fall Hammer, BFH-12A, OZM Rsearch. Available on http://www.ozm.cz/en/sensitivity-tests/bam-fall-hammer-bfh-12a/

6. C. Jitea, G Vasilescu, R. Laszlo, C. Radeanu, Proceedings of the 19th International Multidisciplinary Scientific Geoconference SGEM 2019 19, 725-732 (2019) 